\title{
Aleitamento materno exclusivo em tempos de pandemia da COVID-19: revisão integrativa
}

\author{
Exclusive breastfeeding in COVID-19 pandemic times: integrative review \\ Lactancia materna exclusiva en tiempos de pandemia COVID-19: revisión integrativa
}

Recebido: 20/02/2021 | Revisado: 27/02/2021 | Aceito: 08/03/2021 | Publicado: 16/03/2021

Regina Consolação dos Santos ORCID: https://orcid.org/0000-0002-7393-7210 Universidade de Itaúna, Brasil

E-mail: reginasantos72@outlook.com

Ronnara Cristina Costa Amaral ORCID: https://orcid.org/0000-0003-3173-8510 Universidade do Estado de Minas Gerais, Brasil E-mail: ronnaraamaral@gmail.com

Edinara Santos

ORCID: https://orcid.org/0000-0003-4175-9286 Universidade do Estado de Minas Gerais, Brasil E-mail: edinarasantosenfe@gmail.com

Thayane Vieira Carvalho ORCID: https://orcid.org/0000-0001-8644-8954 Clínica Auge, Brasil

E-mail: thayanevieira100@yahoo.com.br Thays Lorena Bahia Vieira Correia ORCID: https://orcid.org/0000-0001-8308-8746 Universidade de Itaúna, Brasil E-mail: lorenathays27@gmail.com

Claudia Martins da Costa ORCID: https://orcid.org/0000-0001-5904-6829 Universidade do Estado de Minas Gerais, Brasil

E-mail: claudiacostamello.92@gmail.com

Heber Paulino Pena

ORCID: https://orcid.org/0000-0002-9122-6827 Universidade de Itaúna, Minas Gerais, Brasil E-mail: heberppena@yahoo.com.br

Samuel Barroso Rodrigues

ORCID: https://orcid.org/0000-0002-9838-5510 Universidade de Itaúna, Brasil

E-mail: silmara.andrade@uemg.br

Silmara Nunes Andrade

ORCID: https://orcid.org/0000-0002-1975-0827

Universidade do Estado de Minas Gerais, Brasil E-mail: silmara.andrade@uemg.br

\begin{abstract}
Resumo
Introdução: O aleitamento materno exclusivo (AME) é visto como uma das linhas de cuidado prioritárias na Saúde Pública como estratégias para redução da mortalidade infantil em todo o mundo. A transmissão do corona-vírus se dá, segundo epidemiologia, de forma horizontal, de pessoa a pessoa, por contato direto ou indireto com secreções contaminadas geradas ao falar, espirrar ou tossir, e por contato com superfícies contaminadas com o vírus e posteriormente com o toque em mucosas do nariz e boca. Quando contextualizado o aleitamento materno exclusivo com o novo cenário pandêmico causado pelo atual surto de corona-vírus (SARS-CoV-2), ainda se apresenta como uma incógnita, não tendo nenhum estudo comprovando a transmissão pelo leite materno. Métodos: Refere-se a uma revisão integrativa da literatura adotando como fonte de informação as bases eletrônicas de dados. Resultados: $\mathrm{O}$ artigo foi construído com base nos guidelines da metodologia do PreferredReportingItems for Systematic Reviews and Meta-Analyses (PRISMA). Discussão: Não há comprovação científica que o vírus seja transmitido de forma vertical através do leite materno. Considerando os inúmeros benefícios do aleitamento materno, que superam os riscos da COVID-19 nessa população, a amamentação deve ser orientada de maneira adequada, independente de a mãe ser assintomática, suspeita ou confirmada da doença. Considerações finais: Ações educativas e preventivas relacionadas às complicações mamárias são questões necessárias e adequadas para sustentar o processo de amamentar fisiológico perante o momento da pandemia.
\end{abstract}

Palavras-chave: Aleitamento materno; COVID-19; Estratégia de saúde da família. 


\begin{abstract}
Introduction: Exclusive breastfeeding (EBF) is seen as one of the priority lines of care in Public Health as strategies to reduce child mortality worldwide. The transmission of the corona-virus occurs, according to epidemiology, horizontally, from person to person, by direct or indirect contact with contaminated secretions generated when speaking, sneezing or coughing, and by contact with surfaces contaminated with the virus and later with the touch mucous membranes of the nose and mouth. When exclusive breastfeeding is contextualized with the new pandemic scenario caused by the current outbreak of the corona-virus (SARS-CoV-2), it still presents itself as an unknown factor, with no study proving transmission through breast milk. Methods: Refers to an integrative literature review using electronic databases as the source of information. Results: The article was built based on the guidelines of the PreferredReportingItems for Systematic Reviews and Meta-Analyzes (PRISMA) methodology. Discussion: There is no scientific evidence that the virus is transmitted vertically through breast milk. Considering the countless benefits of breastfeeding, which outweigh the risks of COVID-19 in this population, breastfeeding must be properly guided, regardless of whether the mother is asymptomatic, suspected or confirmed of the disease. Final considerations: Educational and preventive actions related to breast complications are necessary and appropriate issues to support the physiological breastfeeding process in the face of the pandemic.
\end{abstract}

Keywords: Breast feeding; COVID-19; Family health strategy.

\title{
Resumen
}

Introducción: La lactancia materna exclusiva (LME) es vista como una de las líneas de atención prioritarias en Salud Pública como estrategias para reducir la mortalidad infantil a nivel mundial. La transmisión del coronavirus se produce, según epidemiología, de forma horizontal, de persona a persona, por contacto directo o indirecto con secreciones contaminadas generadas al hablar, estornudar o toser, y por contacto con superficies contaminadas con el virus y posteriormente con el tacto. membranas mucosas de la nariz y la boca. Cuando la lactancia materna exclusiva se contextualiza con el nuevo escenario pandémico provocado por el brote actual del coronavirus (SARS-CoV-2), todavía se presenta como un factor desconocido, sin estudios que demuestren la transmisión a través de la leche materna. Métodos: se refiere a una revisión integradora de la literatura utilizando bases de datos electrónicas como fuente de información. Resultados: El artículo se construyó con base en las pautas de la metodología PreferredReportingItems para revisiones sistemáticas y metaanálisis (PRISMA). Discusión: No existe evidencia científica de que el virus se transmita verticalmente a través de la leche materna. Teniendo en cuenta los innumerables beneficios de la lactancia materna, que superan los riesgos del COVID-19 en esta población, la lactancia materna debe ser guiada adecuadamente, independientemente de que la madre esté asintomática, sospechada o confirmada de la enfermedad. Consideraciones finales: Las acciones educativas y preventivas relacionadas con las complicaciones mamarias son aspectos necesarios y adecuados para apoyar el proceso fisiológico de la lactancia materna ante la pandemia.

Palabras clave: Amantamiento; COVID-19; Estrategia de salud familiar.

\section{Introdução}

O aleitamento materno exclusivo (AME) é visto como uma das linhas de cuidado prioritárias na Saúde Pública como estratégias para redução da mortalidade infantil em todo o mundo (Passos, B. C. M.., et al, 2021). Benéfico para a mulher e para o desenvolvimento do bebê, considerado padrão ouro na alimentação do lactante, o leite materno é composto por proteínas, gorduras e carboidratos (Brasil, 2020 \& Oliveira, 2011).

Além disso, é econômico e de eficaz intervenção para redução da morbimortalidade infantil, contribuindo assim, para a redução da prevalência de doenças. Quando o aleitamento é realizado conforme recomendado, proporciona ao recém-nascido um crescimento e desenvolvimento adequados, fortalece o sistema imune e previne algumas doenças prevalentes na infância e na fase adulta (Brasil, 2015).

Mesmo tendo conhecimento sobre esses benefícios, apenas $40 \%$ das crianças no mundo recebem o AME até os seis meses de vida, segundo pesquisa realizada em 2019 pela United Nations International Children's Emergency Fund-UNICEF (WHO, 2017). Em países com o desenvolvimento econômico mais estabilizado, esse número chega a ser ainda mais baixo, apresentando um total de 23,9\% dos bebês amamentados exclusivamente (WHO, 2020).

Segundo o Ministério da Saúde, no Brasil 67,7\% das crianças mamam na primeira hora de vida e a duração média do Aleitamento Materno Exclusivo é de 54 dias, ou seja, menos de dois meses. Aproximadamente apenas $41 \%$ das crianças menores de seis meses tiveram alimentação exclusivamente por leite materno no país (Brasil, 2020). 
Desde a gravidez a mulher sofre diversas transformações, na qual vive cercada de sensações e sentimentos diversificados e contraditórios, gerando medos e anseios quanto aos cuidados com o seu bebê. Sendo assim, a orientação às gestantes sobre o AME deve ser iniciada logo nas primeiras consultas de pré-natal, buscando assegurar o desenvolvimento da gestante, abordando aspectos psicossociais e as atividades educativas e preventivas, e principalmente a conscientização e preparo para o AME (Brasil, 2012; Nascimento, Teodoro, Vidal \& Pinto, 2017). Destaca-se importante o papel dos profissionais da atenção básica de saúde no acompanhamento, orientação e incentivo ao aleitamento materno exclusivo durante todo o pré-natal, proporcionando às gestantes e aos bebês um atendimento capacitado e multiprofissional (Parada, Carvalhaes, Cesar, Wickler \& Wickler, 2005).

Nota-se um despreparo das mulheres quando o assunto é o AME, que acabam não realizando devido às dificuldades enfrentadas, como as lesões no bico do peito, ingurgitamento mamário, percepção da oferta insuficiente do leite da mãe, demora na apojadura e o retorno precoce ao trabalho, causando o desmame precoce da criança, (Barbosa et al., 2017; Chimionato, Chaude \& Pinto, 2008).

As Corona-vírus (CoVs) são um grupo de doenças pertencentes a 04 tipos de famílias de vírus: Arterivíridae, Mesonivíridae, Ronivíridae e o Coronavíridae. A família Coronavíridae era composta por 07 vírus capazes de causar doenças na população humana, porém, em 2019, um novo membro denominado SARS-CoV-2, dessa família deu origem ao Coronavírus-2019 popularmente denominado por COVID-19 (Bezerra et al., 2020).

Os corona-vírus recebem esse nome devido a sua aparência semelhante a uma coroa solar (corona solaris), são envelopados, possuem RNA de cadeia simples (27.000 a 32.000 pares de bases) e sentido positivo, com estrutura helicoidal flexível e estabilizado pela proteína N, medindo de 80 a 160nm (Zou et al., 2020).

A transmissão do vírus do corona-vírus se dá, segundo a epidemiologia, de forma horizontal, de pessoa a pessoa, por contato direto ou indireto com secreções contaminadas geradas ao falar, espirrar ou tossir, e por contato com superfícies contaminadas com o vírus e posteriormente com o toque em mucosas do nariz e boca (Bai et al., 2020).

Quando contextualizado o aleitamento materno exclusivo com o novo cenário pandêmico causado pelo atual surto de corona-vírus (SARS-CoV-2), ainda se apresenta como uma incógnita, não tendo nenhum estudo comprovando a transmissão pelo leite materno Segundo a OMS, o leite materno juntamente com o contato pele-a-pele superam substancialmente os potenciais riscos da transmissão e doença associadas à COVID-19 (WHO, 2020).

Entretanto, ainda sim existem necessidades de atenção durante a amamentação caso a mãe seja suspeita de ter sido infectada pelo COVID-19. A OMS traz uma "Arvore de decisão" para a amamentação no contexto da COVID-19, contendo orientações para os cuidados de saúde e em contextos comunitários. Esse fluxograma diz sobre a higienização das mamas, mãos, tórax, bem como o uso de máscara e respeitando o distanciamento após a amamentação (WHO, 2020).

Partindo pelo pressuposto das diversas dificuldades encontradas pela puérpera para a realização do AME, com o agravante do cenário pandêmico, torna-se necessário verificar a percepção das mães diante desse cenário (Nascimento, Teodoro, Vidal \& Pinto, 2017).

Dessa forma, o presente estudo buscou-se identificar as incompreensões e incertezas das puérperas frente à transmissibilidade do SARS-CoV-2 pelo leite materno: revisão da literatura.

\section{Metodologia}

A metodologia da pesquisa é a parte do texto que envolve uma variedade e quantidade de tópicos, possibilitando as respostas relevantes da pesquisa, relatando como acontecerá a pesquisa, a quantidade de informação e as ferramentas que serão utilizadas (Marconi \& Lakatos, 2003).

Este trabalho refere-se a uma revisão integrativa da literatura, de caráter qualitativo, onde há uma abordagem 
metodológica a ser seguida, contendo variados conjuntos de obras literárias existentes que são avaliadas e interpretadas pelo pesquisador. Sua utilização está em grande número, no território de formação acadêmica no campo das Ciências Sociais e Humanas da Saúde (Mendes, Silveira \& Galvão, 2008; Pereira, Shitsuka, Parreira \& Shitsuka, 2018). Foram utilizados artigos e revistas de caráter científico, com o objetivo de colher informações, necessárias para discussão do tema.

Para tanto, foram adotadas como fonte de informação as bases eletrônicas de dados como: Base de Dados Bibliográficos Especializada na Área de Enfermagem (BDENF), Medical Literature Analysisand Retreval System Online (MEDLINE), PUBMED, Google Acadêmico, Biblioteca Virtual da Saúde (BVS), ScientificElectronic Library Online (SCIELO), Ministério da Saúde, Organização Mundial de Saúde (OMS), e outras literaturas eletrônicas e não eletrônicas.

Os descritores utilizados na realização das buscas foram Aleitamento Materno Exclusivo, Estratégia de Saúde da Família, COVID-19, Breast feeding, Family Health e Strategy.

Os critérios estabelecidos para a inclusão dos trabalhos foram: artigos publicados nos idiomas português e inglês. Foram excluídos os artigos repetidos, incompletos e que não se enquadravam ao tema proposto.

\section{Resultados}

O artigo foi construído com base nos guidelines da metodologia do Preferred Reporting Items for Systematic Reviews and Meta-Analyses (PRISMA). A seleção de artigos para composição da presente revisão integrativa foi organizada no Fluxograma 1.

Fluxograma 1 - Seleção de artigos por estatégias de busca. Divinópolis, Minas Gerais, 2020.

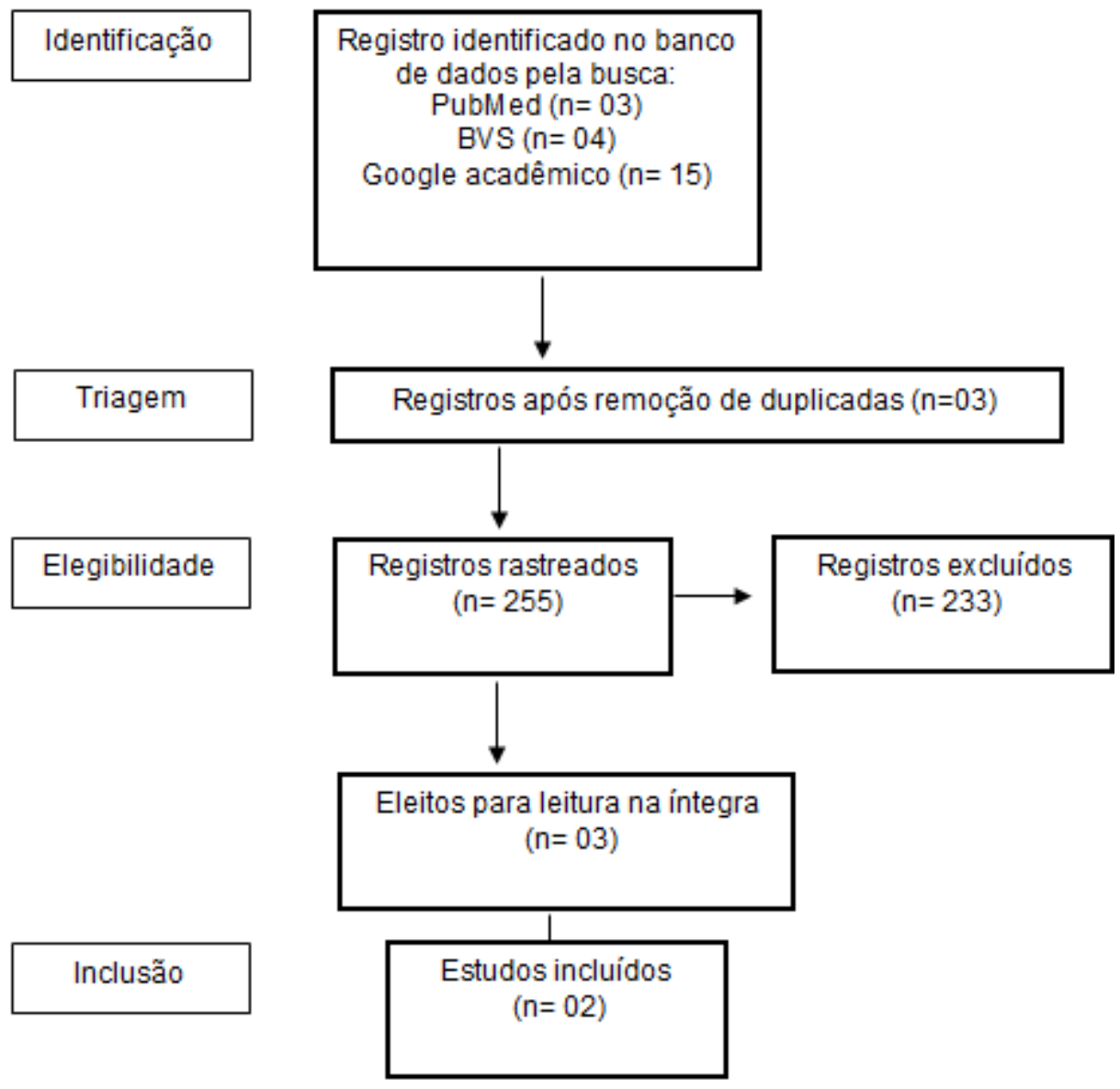

Fonte: Autores (2020). 
No fluxograma acima, observa-se o caminho utilizado para chegar aos estudos incluídos nessa pesquisa, destacando, de forma resumida, a quantidade de artigos excluídos.

\section{Discussão}

O resgate da cultura do AME vem sendo reforçado através da tese de que o leite humano (LH) é o alimento mais natural e seguro para a criança, resgate esse que permite às mulheres vencer as barreiras existentes e fazer a melhor escolha na hora de nutrir seus filhos. $\mathrm{O}$ aleitamento materno exclusivo é recomendado até os primeiros meses de vida do bebê, sendo considerado o jeito mais seguro de alimentação, pois favorece o ganho de peso, a redução do risco de doenças imunológicas, redução da mortalidade, entre outros. Não existe modo artificial capaz de reproduzir os efeitos completos e dinâmicos das substâncias contidas no leite humano (Silva, 2014).

De acordo com pesquisa feita por Carreiro et al., 2018, o Aleitamento Materno Exclusivo foi praticado por 72,6\% das mulheres atendidas nos primeiros 30 dias após o parto. Essas mulheres tiveram em comum a percepção materna quanto à quantidade de leite produzida, sobre o posicionamento materno e o da criança, a preensão, sucção e deglutição da criança de forma adequada e algumas variáveis como: escolaridade maior, relacionamento conjugal estável, experiência prévia com aleitamento materno, mamilos protusos, entre outros. Nesse estudo, foram analisados 1608 prontuários de mulheres gestantes atendidas entre os anos de 2004 e 2016 no ambulatório especializado em aleitamento materno na Universidade Federal de São Paulo (Carreiro, 2018).

Em pesquisa feita por Azevedo et al. (2015) com mulheres em aleitamento materno e que realizaram o pré-natal em Unidades Básicas de Saúde da Família no município de Campina Grande - PB, no período de abril a maio de 2013, obtiveram resultados que apontam para o pouco conhecimento das nutrizes em relação ao vínculo afetivo com a criança, os gastos da família com a alimentação da criança e o risco de hemorragias pós-parto. Outro fator influenciável é a produção insuficiente de leite, a dificuldade de pega da mama e diversas intercorrências mamárias após o parto. Fica evidente diante das informações apresentadas que é necessário expandir as orientações e o apoio ao Aleitamento Materno Exclusivo, dando apoio às nutrizes nas primeiras semanas pós-parto (Azevedo, 2015).

Conforme Sassa et al, (2014) o aleitamento materno pode trazer vantagens como propriedades nutritivas e imunológicas que temos no leite humano, que favorecem a maturação gastrintestinal, o fortalecimento do vínculo entre mãe e filho, o desenvolvimento neuropsicomotor, proteção antioxidante, diminuição no risco de infecções, menos tempo de hospitalização e incidência de reinternações, se for o caso (Sassá, 2014).

O que fica claro é que os nutrientes do leite materno são primordiais para os primeiros dias de vida do bebê e também, para a constituição imunológica do sujeito nos anos seguintes. Mas é preciso criar formas de promover o Aleitamento Materno Exclusivo para que todas as mães tenham acesso à informação e também ao auxílio com um profissional de enfermagem competente (Martins-Filho, Santos \& Santos Jr, 2020).

Um estudo realizado com mulheres grávidas que contraíram COVID-19 sobre amamentar ou não amamentar mostrou que as nutrizes trazem a experiência física da dor na mama ao falarem sobre os desafios do período de amamentação. Os problemas relacionam-se com o pós-operatório e também com a falta de preparo e orientação das mães. O ingurgitamento e as fissuras mamárias são aspectos que dificultam o sucesso da amamentação, o que faz com que a prevenção seja algo importante para intervenção do desmame precoce (Martins-Filho, Santos \& Santos Jr, 2020).

O leite materno é alimento completo para o bebê e é indicado como único alimento até os seis meses de vida, sendo de grande importância para a sobrevivência, pois atende às necessidades nutricionais, psicológicas e imunológicas da criança. Os bebês que são alimentados pelo leite materno são considerados mais inteligentes e têm melhor desempenho na fase escolar (WHO, 2020). 
Bebês prematuros correm alto risco nutricional devido a poucas reservas de nutrientes, entre outros, sabe-se que a maioria das reservas de nutrientes fetais são depositadas, durante os três últimos meses de gravidez, assim, o lactente prematuro já começa a vida com o estado nutricional comprometido (Silva et al., 2014).

O leite humano começa a fluir dentro de 48 a 96 horas após o parto, sendo o chamado colostro mais rico em proteínas e mais pobre em gordura e carboidratos do que o leite maduro, contendo também anticorpos em sua composição (Silva et al., 2014; Sassá et al., 2014).

O Ministério da Saúde Brasileiro reconhece o leite humano como alimento benéfico para a criança, com inúmeras vantagens na alimentação de pré-termos. Assim, o recém-nascido se beneficia do leite materno em detrimento aos esforços que precisa fazer para se adaptar a vida fora do útero (Brasil, Ministério da Saúde, 2020; WHO, 2020).

A Organização Mundial da Saúde (OMS) recomenda o aleitamento materno exclusivo nos primeiros seis meses de vida, seguido por continuação do aleitamento e complementação alimentar adequada por até 2 anos ou mais. O contato que o aleitamento proporciona, entre o binômio mãe e filho também são interpretados, pela Organização Mundial de Saúde como algo positivo para a relação dos dois, porém, diante da pandemia de COVID-19, há motivos para se preocupar com o fato da possibilidade das mães com a doença transmitirem o vírus SARS-CoV-2 para os bebês ou crianças pequenas através do aleitamento. Diante disso, a Organização Mundial de Saúde recomenda cuidados maiores sobre o contato mãe-bebê e aleitamento baseado nos riscos potenciais do COVID-19 para o bebê e também nos riscos de morbidade e mortalidade associados ao não aleitamento, não contato com a mãe, e todos os demais riscos (Martins-Filho, Santos \& Santos Jr, 2020).

A COVID-19 (SARS-CoV-2) tem sua transmissão por gotículas respiratórias, fluidos biológicos e saliva. No entanto, há brechas impostas sobre a presença do vírus no leite materno de mulheres grávidas acometidas pela doença. Estudos recentes apontam que amostras colhidas de trato respiratório superior de neonatos e tecidos placentários do nascimento não apresentam presença da doença. Testes também foram feitos no leite materno, dando o mesmo resultado negativo para a doença. Mas há que se atentar para não haver generalização dessas informações, pois estudos referentes ao tema ainda são recentes e se fazem necessários novas amostras e meios de mensurar tudo isso (Passos et al., 2021; Bezerra et al., 2021).

A OMS, e o Fundo das Nações Unidas para a Infância (UNICEF) e o Ministério da Saúde do Brasil (MS) falam de uma amamentação exclusiva nos primeiros 6 meses de vida e a complementar até os 2 anos de idade ou mais, devendo introduzir alimentos sólidos de qualidade e em tempo oportuno, trazendo inúmeros benefícios para a saúde das crianças em suas etapas de desenvolvimento (Brasil, 2015).

O Ministério da Saúde recomenda manter a amamentação em caso de infecção pela COVID-19, desde que a mãe escolha amamentar e apresente condições clínicas para o ato (Brasil, 2020). Não há comprovação científica que o vírus seja transmitido de forma vertical através do leite materno. Considerando os inúmeros benefícios do aleitamento materno, que superam os riscos da COVID-19 nessa população, a amamentação deve ser orientada de maneira adequada, independente de a mãe ser assintomática, suspeita, ou confirmada da doença (SBP, 2020).

Recomendações devem ser transmitidas à população para evitar a disseminação do vírus através de gotículas respiratórias, como: realizar lavagem das mãos com água e sabão no mínimo 20 segundos antes e depois de tocar o bebê; realizar higienização das mamas antes e após cada mamada; fazer uso de máscara (cobrindo nariz e boca) durante a amamentação e evitar falar, tossir ou espirrar nesse momento; deve-se trocar imediatamente a máscara em caso de espirro ou tosse e em cada mamada; não permitir que o bebê toque o rosto da mãe; em caso de mães suspeitas ou confirmadas de COVID19, todos os cuidados com o bebê devem ser realizados por outra pessoa que não tenha sintomas, que não seja suspeita ou confirmada; utilizar luvas cirúrgicas ou descartáveis na troca de fraldas (Brasil, 2020).

Atrelado a isso, as mudanças sociais e econômicas sofridas pela sociedade em tempos de pandemia aumentaram as dificuldades das famílias em manter uma alimentação adequada. Além disso, a urbanização cria famílias dependentes de 
empregos informais com rendimentos incertos, sem proteção legal à maternidade (Oliveira, 2011). Esse cenário é um desafio para o profissional de saúde no apoio ao aleitamento materno, que não implica somente no conhecimento teórico sobre a real necessidade daquelas mães, mas também nas habilidades e atitudes para acolher dúvidas, preocupações, dificuldades e ter uma escuta ativa com essas mães e seus familiares. Assim, poderá levar empatia, percepção e disponibilidade para criar ações factíveis e congruentes ao contexto familiar (Nascimento, Teodoro, Vidal \& Pinto, 2017).

Nos últimos meses, temos passado por período de isolamento social diante do surto de COVID-19 (SARS-CoV-2). Analisando o impacto disso nas lactantes vemos poucos estudos na área e analogias dialéticas. Mas de forma geral, os resultados não apontam para uma contaminação do leite materno diante de uma mãe diagnosticada com a doença, nem mesmo no parto. Estudos tem comprovado que não se transmite o vírus ao feto durante a gravidez e nem mesmo durante o parto (Martins-Filho, Santos \& Santos Jr, 2020).

Por ser um assunto recente, o COVID-19 ainda vem sendo pesquisada por cientistas do mundo todo em prol de uma vacina, um tratamento ou cura. Diante do fracasso desta busca, outros aspectos em relação a este vírus, como as interferências que ele causa na vida de mães que estão amamentando, acabam não sendo alvo também de pesquisas. $\mathrm{O}$ foco é eliminar a doença, então, possíveis prejuízos causados pelo vírus acabam ficando em segundo plano (WHO, 2020).

Nota-se o quanto se faz necessário e importante à busca por novas estratégias, com objetivos pré-estabelecidos do AME, como a promoção, segurança, proteção e apoio às nutrizes. Algumas estratégias utilizadas apontam para a criação de cartilhas, vídeos educativos, oficinas de grupo e demais tipos de apoios, suporte e orientação necessários para a eficácia do Aleitamento Materno Exclusivo (Brasil, 2013; Bezerra et al., 2021).

As influências da sociedade são fatores relevantes para a introdução precoce ou não de outros alimentos, como água, chás e outros tipos de leites. Através de orientações de profissionais da saúde, como os enfermeiros, as mães conseguem tomar decisões baseadas em orientações de saúde precisas, mantendo a amamentação materna exclusiva pelo tempo hábil (SBP, 2020).

A maternidade carrega um cenário limitado sobre a ideia de cuidados com os filhos, sendo a mulher a principal responsável por engravidar e amamentar. Assim, o contexto mostra que profissionais de saúde podem desmistificar este tipo de contexto e trazerem práticas que promovam o aleitamento materno e incentivem o apoio da família antes, durante e depois da gravidez, se tornando a rede familiar o apoio à mulher durante o puerpério. Além dos profissionais das redes básicas de apoio à saúde, os familiares e vizinhos também são fontes importantes de orientação para essas mães, sendo bases sólidas para as puérperas (Bai et al., 2020).

Há também a perspectiva da obtenção de bons resultados com o aconselhamento em amamentar, que consiste em o profissional enfermeiro estar preparado para tal demanda e ação. Diante dessas necessidades, o profissional torna-se um destaque na prática clínica como um facilitador e disseminador para o alcance das mães em amamentar (WHO, 2020).

Devida a baixa quantidade de artigos para esse estudo, encontramos dificuldades para o desenvolvimento de uma discussão mais profunda sobre a temática abordada.

\section{Considerações Finais}

Contudo, há que se pensar como o Aleitamento Materno Exclusivo pode fazer parte das políticas públicas de saúde, visando aumentar os índices do mesmo, e assim contemplar a todas as mães que procuram o serviço público de saúde.

Nota-se ainda que o AME relacionado ao COVID-19 ainda é pouco estudado, devido ao fato de que a conjectura do COVID-19 é recente e carece de material teórico, para que estudantes e profissionais da área e até mesmo para que mães possam estudar e compreender melhor essa parte da maternidade frente à pandemia. 
O manejo das complicações enfrentadas pelas mães é uma tarefa feita pelos enfermeiros e deve estar à frente do processo de educação em saúde com orientações precisas e imparciais, desenvolvendo um trabalho essencial na decisão de amamentar por parte da mãe e orientações relacionadas ao contexto COVID-19.

Assim, ações educativas e preventivas relacionadas às complicações mamárias são questões necessárias e adequadas para sustentar o processo de amamentar fisiológico perante o momento da pandemia que estamos vivenciando e trazer relações de confiança, compromisso e vínculo com o profissional da saúde, a mãe e a rede sócio afetiva. Diante do exposto, evidenciase a importância do acompanhamento e incentivo a grupos de apoio na estratégia de saúde da família e ambiente hospitalar (maternidade), que ofereça orientação adequada para puérperas durante o processo de aleitamento exclusivo.

Como trabalhos futuros, espera-se que as pesquisas sobre a COVID-19 sejam intensificadas para que mais estudos direcionados ao aleitamento e cuidados com o recém nascido relacionados à essa doença sejam realizados, garantindo mais informações aos profissionais responsáveis por orientar os pais e responsáveis, permitindo um melhor preparo desses profissionais.

\section{Referências}

Azevedo, A. R. R., Alves, V. H., Souza, R. de M. P. de, Rodrigues, D. P., Branco, M. B. L. R., \& Cruz, A. F. do N. da. (2015). Clinical management of breastfeeding: knowledge of nurses. Escola Anna Nery - Revista de Enfermagem, 19(3), 439-445. https://doi.org/10.5935/1414-8145.20150058

Azevedo, I. C. de, Sales, S. dos S., Ferreira Júnior, M. A., Carvalho, D. P. de S. R. P., Cruz, G. K. P., \& Amaral, L. J. X. (2016). Fatores que influenciam na interrupção do aleitamento materno exclusivo em nutrizes. Revista Gaúcha de Enfermagem, 36, 127-134. https://doi.org/10.1590/1983-1447.2015.esp.56676.

Bai, Y., Yao, L., Wei, T., Tian, F., Jin, D. Y., Chen, L., \& Wang, M. (2020). Presumed Asymptomatic Carrier Transmission of COVID-19. JAMA, 323(14), 1406-1407. https://doi.org/10.1001/jama.2020.2565

Barbosa, G. E. F., Silva, V. B. da, Pereira, J. M., Soares, M. S., Medeiros Filho, R. dos A., Pereira, L. B., Pinho, L. de, \& Caldeira, A. P. (2017). Dificuldades Iniciais Com a Técnica Da Amamentação E Fatores Associados a Problemas Com a Mama Em Puérperas Tt - Initial Breastfeeding Difficulties and Association With Breast Disorders Among Postpartum Women. Revista Paulista de Pediatria, 35(3), 265-272. Doi.org/10.1590/1984-0462/;2017;35;3;00004

Bezerra, A. D. C., Morais, K. de C., Alencar, M. de, Sales Junior, R. de O., Machado, A. L. L. B., Alves, R. de C. L., Costa, D. E. S., Lima, M. A. G. de, Mendes, L. S. F., Santos, D. C. dos, \& Silva Filho, L. S. da. (2021). Criação e utilização de tecnologias para enfrentamento da COVID-19 frente ao período de pandemia. Research, Society and Development, 10(2), e5210212225. https://doi.org/10.33448/rsd-v10i2.12225

Bezerra, V. de L., Anjos, T. B. dos, Souza, L. E. S., Anjos, T. B. dos, Vidal, A. M., \& Silva Júnior, A. A. da. (2020). SARS-CoV-2 como agente causador da COVID-19: Epidemiologia, características genéticas, manifestações clínicas, diagnóstico e possíveis tratamentos. Brazilian Journal of Health Review, 3(4), 8452-8467. https://doi.org/10.34119/bjhrv3n4-097

Brasil. Ministério da Saúde. (2013). Estratégia Nacional para Promoção do Aleitamento Materno e AlimentaçãoComplementar Saudável no Sistema Único de Saúde (SUS) -Estratégia Amamenta e Alimenta Brasil. In Https://Bvsms.Saude.Gov.Br/Bvs/Saudelegis/Gm/2013/Prt1920_05_09_2013.Html: Vol. Cartilha s. https://bvsms.saude.gov.br/bvs/saudelegis/gm/2013/prt1920_05_09_2013.html

Brasil. Ministério Da Saúde (2018). Ministério da Saúde lança Campanha de Amamentação. Agência Saúde. <http://www.saude.gov.br/noticias/agenciasaude/43891-ministerio-da-saude-lanca-nova-campanha-de-amamentacao>.

Brasil. Ministério da Saúde. Secretaria de Atenção à Saúde. (2013). Departamento de Ações Programáticas Estratégicas. Atenção humanizada ao recémnascido de baixo peso: Método Canguru: manual técnico (2a ed.), Editora do Ministério da Saúde, 2013. <http://www.saude.gov.brlbvs\publicacoeslatencaohumanizada-recem-nascido-canguru.pdf >.

Brasil. Ministério da Saúde (2020) Orientações direcionadas ao Centro de Operações de Emergências para o Corona-vírus (COE COVID-19), a serem adotadas pelo Sistema Único de Saúde (SUS) para a amamentação em eventuais contextos de transmissão de síndromes gripais. Nota Técnica $N^{\circ} 9 / 2020$ DAPES/SAPS/MS. http://189.28.128.100/dab/docs/portaldab/documentos/notatecnicaamamentacao92020DAPE SAPSMS03abr2020COVID-19.pdf

Brasil, Ministério da Saúde, Secretaria de Atenção à Saúde, \& Departamento de Atenção Básica. (2015). Saúde da criança: aleitamento materno e alimentação complementar. In Cadernos de Atenção Básica (Issue 23).

Carreiro, J. A., Francisco, A., A., Vilhena, A. C. F., Abuchaim, M. K. O., Vieira, E. S. \& Coca, K. P. (2018). Dificuldades relacionadas ao aleitamento materno: análise de um serviço especializado em amamentação. Acta Paulista de Enfermagem, 31(4), 430-438. https://doi.org/10.1590/1982-0194201800060

Chimionato, L. A., Chaude, L. M., Pinto, I. C. (2008). Saúde da família, pré-natal e amamentação: percepção das mães sobre as dificuldades em amamentar. Investigação, v, 8 n. 1-3 Jan./Dez. 16-25. DOI: https://doi.org/10.26843/investigacao.v8i1-3.67

Despacho n. ${ }^{\circ}$ 5613/2015. (2015). Ministério da Saúde. Diário Da República, $2 .^{a}$ Série - n. $^{\circ} 102$ (27-05-2015), 13550-13553.

Muñoz, I. S., Maria, A., Takayanagui, M.., Sweatman, O. S., \& Benedita, (2002). Revisão sistemática de literatura e metanálise: Noções básicas sobre seu desenho, interpretação e aplicação na área da saúde. An. 8 Simp. Bras. Comum. Enferm. May. 
Macedo, M. D. da S., Torquato, I. M. B., Trigueiro, J. V. S., Albuquerque, A. M. de, Pinto, M. B., \& Nogueira, M. F. (2015). Artigo Original Aleitamento Materno: Identificando a Prática, Benefícios E Os Fatores De Risco Para O Desmame Precoce Breastfeeding: Identifying the Practice , the Benefits and the Risk Factors. Revista de Enfermagem UFPE On Line, 9(1), 414-423. https://doi.org/10.5205/reuol.5221-43270-1-RV.0901sup1201521

Marconi, M., \& Lakatos, E. (2003). Fundamentos de metodologia científica. In Editora Atlas S. A. https://doi.org/10.1590/S1517-97022003000100005

Mendes, K. D. S., Silveira, R. C. de C. P., \& Galvão, C. M. (2008). Revisão integrativa: método de pesquisa para a incorporação de evidências na saúde e na enfermagem. Texto \& Contexto - Enfermagem, 17(4), 758-764. https://doi.org/10.1590/s0104-07072008000400018

Nascimento, M. C., Teodoro, L., Vidal, E., \& Pinto, A. (2017). Concepções e práticas para o aleitamento materno: revisão integrativa. Revista de Enfermagem UFPE on line, 11(3), 1520-1527. https://doi.org/10.5205/1981-8963-v11i3a13997p1520-1527-2017

Martins-Filho P. R., Santos V. S \& Santos Jr. H. P. (2020). To breastfeed or not to breastfeed? Lack of evidence on the presence of SARS-CoV-2 in breastmilk of pregnant women with COVID-19. Rev Panam Salud Publica. 44:e59. https://doi.org/10.26633/RPSP.2020.59

ONU Brasil. (2018). Ministério da Saúde lança nova campanha de incentivo à amamentação.

Oliveira, M. F. D. (2011). Metodologia científica: Um manual para a realização de pesquisas em administração. Manual (pós-graduação) P. 15-30. Catalão Goiás UFG. https://files.cercomp.ufg.br/weby/up/567/o/Manual_de_metodologia_cientifica_-_Prof_Maxwell.pdf

Organização Mundial da Saúde (2020) Aleitamento materno e a doença causada pelo novo coronavírus (COVID-19). <https://iris.paho.org/handle/10665.2/52479>.

Passos, B. C. M., Pimenta, L. T., Silva, M. A., Carvalho, T. V., Vieira, T. L. B., Dias, S. B., Santos, R. C., Pena, H. P. (2021). Perfil das causas básicas de mortalidade neonatal no Brasil, período 2008-2013: revisão integrativa. Iosr Journal of Nursing and Health Science, 10(1), 41-47. 10.9790/1959-1001014147.

Parada C. M. G. L., Carvalhaes M. A. B. L., Cesar, C., Wickler, A. L., \& Wickler, V. C., (2005). Situação do aleitamento materno em população assistida pelo Programa de Saúde da Família - PSF. Revista Latino-Americana Enfermagem; 13(3): 407-14. https://www.redalyc.org/pdf/2814/281421844016.pdf

Pereira, A. S., Shitsuka, D. M., Parreira, F. J., \& Shitsuka, R. (2018). Metodologia da pesquisa científica.

Quart, A. (2019). Pre-Natal. Thoughts and Prayers, 32-33. https://doi.org/10.2307/j.ctvq4c0bc.11.

Silva, R. K. C., Souza, N. L. de, Silva, R. A. R. da, Silva, J. B., Ladisláo, N. B. P. R., \& Oliveira, S. I. M. de. (2014). O ganho de peso em prematuros relacionado ao tipo de leite. Revista Eletrônica de Enfermagem, 16(3), 535-541. https://doi.org/10.5216/ree.v16i3.21748

Sassá, A. H., Schmidt, K. T., Rodrigues, B. C., Ichisato, S. M. T., Higarashi, I. H., \& Marcon, S. S. (2014). Bebês pré-termo: aleitamento materno e evolução ponderal. Revista Brasileira de Enfermagem, 67(4), 594-600. https://doi.org/10.1590/0034-7167.2014670415

Sociedade Brasileira de Pediatria (2020). Aleitamento Materno em tempos de COVID-19 - recomendações na maternidade e após a alta. Nota de alerta. Departamento Científico de Aleitamento Materno, SBP. https://www.sbp.com.br/fileadmin/user_upload/22467f-NA_-_AleitMat_tempos_COVID-19_na_matern_e_apos_alta.pdf

World Health Organization (WHO). (2017) "United Nations International Children's Emergency Fund (UNICEF)." Democratic Republic of the Congo cVDPV2 Outbreak Situation Report.

World Health Organization 2020. Frequentl yasked questions: Breastfeedingand COVID-19 for health care workers. https://http://www.who.int/docs/defaultsource/maternal-health/faqs-breastfeeding-and-covid-19.pdf?sfvrsn=d839e6c0_1

Zou, L., Ruan, F., Huang, M., Liang, L., Huang, H., Hong, Z., Yu, J., Kang, M., Song, Y., Xia, J., Guo, Q., Song, T., He, J., Yen, H. L., Peiris, M., \& Wu, J. (2020). SARS-CoV-2 Viral Load in Upper Respiratory Specimens of Infected Patients. The New England journal of medicine, 382(12), 1177-1179. https://doi.org/10.1056/NEJMc2001737 